\title{
Hialuronidase: uma necessidade de todo cirurgião dentista que aplica ácido hialurônico injetável
}

\author{
Hyaluronidase: a need for all dental surgeon applying injectable hyaluronic acid \\ Hialuronidasa: una necesidad para todos los cirujanos dentales que aplican ácido \\ hialurónico inyectable
}

José Milton de Aquino e Silva Neto ${ }^{1 *}$, João Luiz Tenório Calado ${ }^{1}$, Maria Helena de Albuquerque Silveira Melo ${ }^{1}$, João Francisco Tenório Neto¹.

\section{RESUMO}

Objetivo: Analisar o processo de aplicação da hialuronidase nos recursos terapêuticos relacionados aos efeitos adversos que o ácido hialurônico $(\mathrm{AH})$ injetável pode causar no decorrer do tratamento feito pelo Cirurgião Dentista (CD). Métodos: Foi realizado uma revisão de literatura, com abordagem descritiva e caráter informativo, onde o procedimento de elaboração se deu mediante buscas por literaturas cientificas, em bases de dados, tendo como descritores: A importância da Hialuronidase e a correção de complicações insatisfatórias após aplicação de AH na face. Resultados: Nos últimos anos a utilização do ácido hialurônico, vem sendo utilizado em tratamentos rejuvenescedores como é o caso da harmonização facial, no entanto é observado que em alguns casos o resultado dessa aplicação provoca efeitos indesejáveis, sendo ocasionado desde um eritema a um granuloma e para a diminuição dessas eventuais sintomatologias é aconselhado a aplicação injetável da Hialuronidase, como consequência ocorre a diminuição do excesso do AH no respectivo local de aplicação. Considerações Finais: A hialuronidase é uma enzima imensamente eficaz, em procedimentos de reversão nos resultados indesejáveis da utilização do $\mathrm{AH}$, sendo de extrema importância e responsabilidade os conhecimentos de suas técnicas e princípios ativos pelos Cirurgiões Dentistas.

Palavras-chave: Hialuronoglucosaminidase, Uso terapêutico, Antineoplásicos, Sistema tegumentar, Enzimas.

\section{ABSTRACT}

Objective: The application process of hyaluronidase in therapeutic resources related to the adverse effects that injectable hyaluronic acid (HA) may cause during the treatment performed by the Dentist (CD). Methods: A descriptive and informative literature review was carried out, in which the elaboration procedure was performed by searching for scientific literature in the following descriptors: The importance of hyaluronidase and the correction of unsatisfactory complications after HA application on the face. Results: In recent years the use of hyaluronic acid has been used in rejuvenating treatments such as facial harmonization, however it is observed that in some cases the result of this application causes undesirable effects, being caused from an erythema to a granuloma and to the in order to reduce these possible symptoms, the injectable application of hyaluronidase is advised, as a consequence there is a decrease in the excess of HA in the respective application site. Final Considerations: Hyaluronidase is an immensely effective enzyme in reversing the undesirable results of HA use, being extremely important and responsible the knowledge of its techaniques and active principles by dentists.

Keywords: Hyaluronoglucosaminidase, Therapeutic use, Antineoplastic agents, Integumentary System, Enzymes.

\footnotetext{
${ }^{1}$ Centro Universitário CESMAC (CESMAC), Maceió-Alagoas. ${ }^{\star} E-m a i l:$ Milton_neto_166@hotmail.com
} 


\section{RESUMEN}

Objetivo: Analizar el proceso de aplicación de la hialuronidasa en recursos terapéuticos relacionados con los efectos adversos que el ácido hialurónico invectable $(\mathrm{AH})$ puede causar durante el tratamiento realizado por el dentista (CD). Métodos: Se realizó una revisión descriptiva e informativa de la literatura, en la cual el procedimiento de elaboración se realizó mediante la búsqueda de literatura científica en los siguientes descriptores: La importancia de la hialuronidasa y la corrección de complicaciones insatisfactorias después de la aplicación de HÁ en la cara. Resultados: En los últimos años, el uso de ácido hialurónico se há utilizado en tratamientos rejuvenecedores, como la armonización facial, sin embargo, se observa que en algunos casos el resultado de esta aplicación causa efectos indeseables, causados por un eritema a un granuloma y para reducir estos posibles sintomas, es aconsejable inyectar hialuronidasa, como consecuencia hay una disminución en el exceso de HÁ en el sitio de aplicación respectivo. Consideraciones finales: La hialuronidasa es una enzima inmensamente efectiva para revertir los resultados indeseables del uso de HÁ, siendo extremadamente importante y responsable el conocimiento de sus técnicas y principios activos por parte de los dentistas.

Palabras-clave: Hialuronoglucosaminidasa, Uso terapêutico, Antineoplásicos, Integumento común, Enzimas.

\section{INTRODUÇÃO}

No decorrer dos últimos anos as pessoas cada vez mais vêm buscando por um padrão de beleza imposto pela sociedade, esses padrões não estão relacionados apenas ao corpo como também a beleza orofacial, no entanto, é inegável que a forma de envelhecimento celular ocorre de forma natural com o aumento da idade. A expectativa de vida subiu grandemente durante as últimas décadas, devido aos fatores socioeconômicos, alimentares e não sedentários, provocando assim uma maior preocupação das aparências faciais; diante desse motivo, muitos submetem-se a procedimentos estéticos com o objetivo de diminuir os efeitos adversos que o tempo traz (FERREIRA NR e CAPOBIANCO MP, 2016).

O tecido epitelial é um dos maiores órgãos dos seres humanos, ele circunda todo o corpo onde delimita o meio interno do externo, conseguindo exercer imensuráveis atribuições: sendo uma forma de reguladora de processos térmicos, apresenta inúmeras defesas que combatem microrganismos indesejáveis, possui ótima de regulamentação do fluxo sanguíneo e a mais crucial são as funções sensoriais sobre o controle do calor, frio, pressão, respondendo ligeiramente as dores e tato, tornando-se deste modo um órgão vital e sem ela, o ser humano não teria possibilidade alguma de sobreviver (SCHNEIDER LV, 2000).

No momento atual a Harmonização Facial vem sendo cada vez mais desempenhada pelos Cirurgiões Dentistas, sendo praticada através de novas técnicas, tendo como uma grande perspectiva harmonizar a face da forma mais suavizada e natural, buscando sempre deixar os resultados os mais discretos possíveis, respeitando a idade, o visagismo e anatomia da face de cada paciente, atendendo assim os resultados esperados de minimizar as marcas dos envelhecimentos. O Cirurgião Dentista (CD) mediante do licenciamento para atuação através de residências ou especializações são capazes de praticar tais procedimentos tão específicos, já que essa área é um processo multidisciplinar (RIOS M, 2017).

As substâncias utilizadas para o processo e harmonização facial são de origens vegetais e animais e cada vez mais vem sendo codificadas com o intuito de melhorar cada vez mais o seu nível de potencialidade, (MONTEIRO EO, 2011). Com os grandes avanços científicos realizados com o propósito de melhores resultados os Cirurgiões Dentistas nunca estiveram tão em evidência como nos dias de hoje, esse fator pode ser correlacionado aos resultados dos seus trabalhos excelentes serem compartilhados em redes sociais. A aplicação do Ácido Hialurônico por ser um biopolímero formado pelo ácido glucurônico e a $\mathrm{N}$-acetilglicosamina é bastante utilizado nas indicações de reguladores para o melhoramento estético e funcional, como a distonia e volume facial (RIOS M, 2017).

Contudo, é de se ansiar que possa coexistir no transcorrer do aumento crescente do uso de preenchedores à base de ácido hialurônico $(\mathrm{AH})$, possíveis efeitos não desejáveis, sendo ocorridos por mau manuseio no ato 
da aplicação ou até mesmo por conta de fatores alérgicos. Entretanto mesmo sabendo que essas substâncias possuem o poder de ser biodegradáveis pelo próprio organismo e de que na grande maioria das vezes esses eventuais efeitos indesejáveis sejam apenas inestéticos, possíveis problemas requerem recursos terapêuticos agressivo e ágeis, tendo como principal objetivo minimizar as ameaças de decorrências não esperadas ou até mesmo morbidades. À visto disso, O CD tem que estar preparado e apto para monitorar esses acontecimentos, recorrendo a aplicação de uma enzima que degenere rapidamente e especificamente essa substância, utilizando a hialuronidase (PARK TH, et al., 2011).

A hialuronidase se trata de uma enzima produzida naturalmente no tecido epitelial, mais especificamente na derme que atua no processo de despolimerização do ácido hialurônico onde ocasiona a redução da massa molar do $\mathrm{AH}$, reduzindo a viscosidade da solução e, como resultado, modifica sua viscoelasticidade, por ser um mucopolissacarídeo bastante glutinoso, constituintes essencialmente das moléculas extracelulares e responsáveis por preservar o ajustamento celular, exercendo como cimento. Desse modo, a hialuronidase reduz a viscosidade intercelular e acrescenta passageiramente a absortividade dos tecidos (BALASSIANO LKA e BRAVO BSF, 2014).

Estudos comprovam que a predisposição às eventuais complicações resultantes das aplicações do AH, acontecem eventualmente ocasionando a formações de nódulos e possíveis granulomas no local da aplicação, e o seu conserto acontece através da aplicação local da hialuronidase, pois sua aplicação possibilita aos efeitos mais ligeiro e mais eficiente do que os que são adquiridos com a utilização de corticoides orais ou injetáveis (NERI SRNG, et al., 2013), (FERREIRA NR e CAPOBIANCO MP, 2016)

Em vista que existem inúmeras marcas comerciais e especificidade para a aplicação do AH para o preenchimento e apresentarem uma satisfatória tolerância, não há preenchedor que seja totalmente desprovido de possíveis riscos, e mesmo o profissional sendo capacitado e possua experiência ocasionalmente depara-se com eventual reação que ocorre de forma imediata, sendo ela eritemas e eventos de sangramentos no local aplicado, ou até mesmo respostas tardias como é o caso da nodulação (JUNKINSHOPKINS JM, 2010).

Nesse cenário, é considerável que o Cirurgião Dentista tenha um olhar clinico satisfatório e aprofundado não só no que os pacientes querem, mas sim no que eles realmente precisam para a obtenção de uma boa harmonização facial, estabelecendo condutas e diretrizes ao ser feito as aplicações do $\mathrm{AH}$, sem poder protelar a anamnese e os exames necessário para um satisfatório (GOODMAN GJ, et al., 2015).

Fundamentando esses aspectos, o presente estudo tem como principal objetivo realizar uma revisão de literatura sobre a utilização da hialuronidase pelos Cirurgiões Dentistas em eventuais decorrências de insatisfação dos pacientes, bem como suas propriedades, principais efeitos e os seus benefícios.

\section{METODOLOGIA}

Para o desenvolvimento deste trabalho foi realizada uma revisão integrativa de literatura, sendo feita entre o período de maio de 2019 a outubro de 2019, onde foram analisados artigos publicados em bases de dados eletrônicos LILACS (Literatura Latino Americana e do Caribe em Ciências da Saúde), MEDLINE (Literatura Internacional em Ciência da Saúde) e SCIELO (Scientific Electronic Library Online) e livros que estavam disponíveis nos acervos bibliográficos presentes na biblioteca central do Centro Universitário CESMAC (Centro de Ensino Superior de Maceió).

Foram consultados textos em língua portuguesa e inglesa, que se referiram a aplicação da hialuronidase nos recursos terapêuticos relacionados aos efeitos adversos que o ácido hialurônico (AH) injetável pode ocasionar, tendo como critérios de exclusão os períodos de publicações, os artigos que não estavam na integra, relatos de casos, ensaios não controlados, monografias e os artigos que não possuíam relevância com a temática, sendo selecionados os textos científicos que apresentavam na íntegra o real objetivo do trabalho, observando a importância da hialuronidase na área odontológica, visando o melhor procedimento para a obtenção de resultados satisfatórios e benéficos para o paciente, sendo selecionadas publicações científicas no período entre 2010 e 2019, com ênfase no intervalo entre 2013 e 2019, dispondo dos seguintes 
descritores: A importância da Hialuronidase, a correção de complicações insatisfatórias após aplicação de AH na face e o uso terapêutico da Hialuronoglucosaminidasa.

\section{RESULTADOS E DISCUSSÃO}

Inicialmente, obteve a efetivação de 24 artigos relacionados a aplicação de hialuronidase. Desses, 12 eram duplicados nas referidas bases de dados, restando 12 artigos para a leitura dos títulos, dos quais dois foram eliminados por não equivaler as adequações dos critérios apontados. 10 artigos elegidos para análise dos resumos, três foram excluídos, restando apenas 7 para tomar parte deste estudo. Posteriormente a revisão das referências deste nenhum outro trabalho foi incorporado. Ao fim das investigações dos dados, a revisão foi miscigenada por seis artigos, e o fluxograma da Figura 1 detalha todos os artifícios de busca pelas pesquisas elegidas para a confecção desta revisão.

Figura 1 - Fluxograma dos estudos identificados.

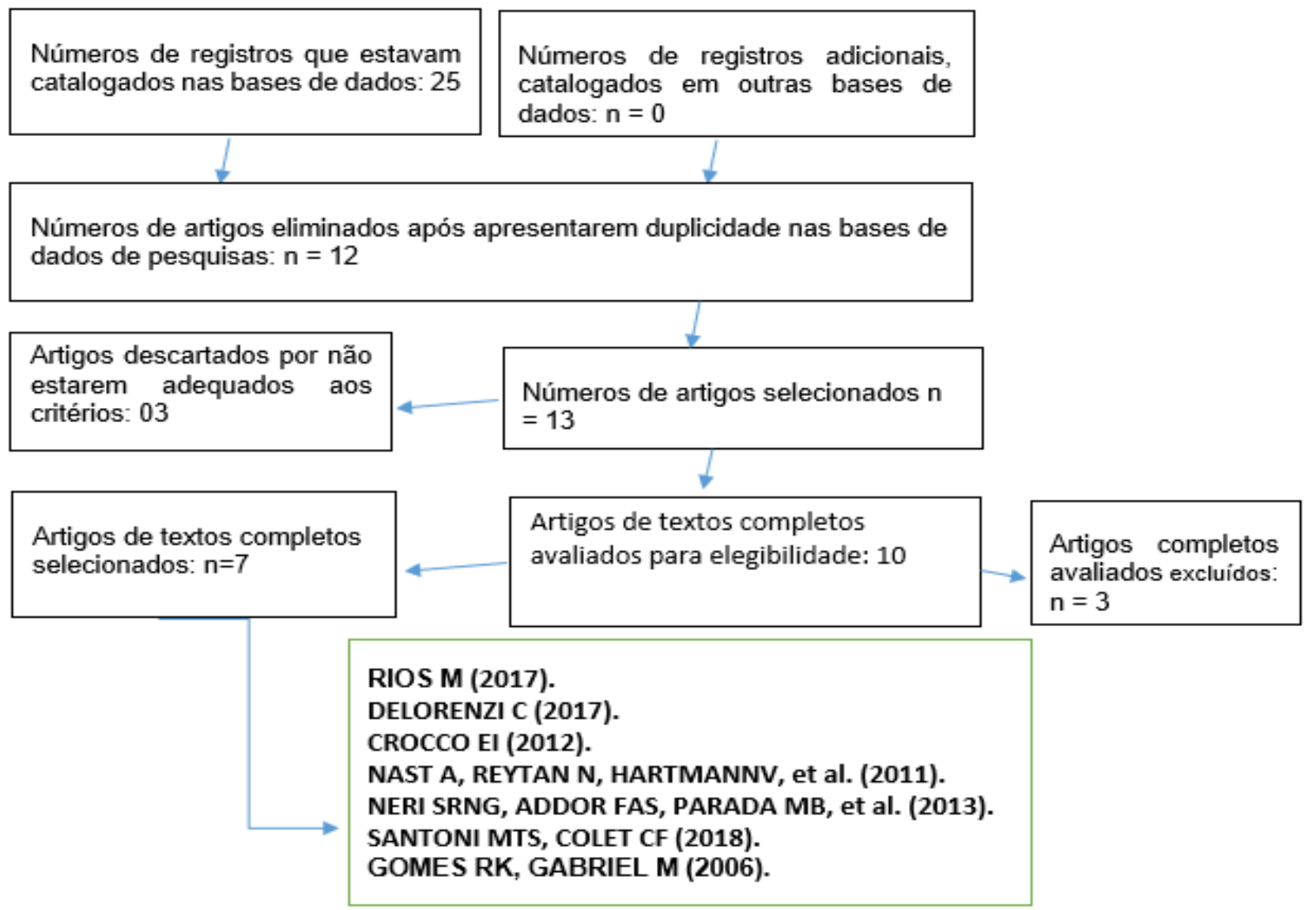

Fonte: Neto JMAS, et al., 2019.

Os artigos possuíram suas informações concentradas nos tópicos: autor/ano, idioma, objetivo e resultados, os quais foram tabulados e apresentados na Tabela 1.

A crescente utilização de harmonização facial utilizando produtos injetáveis cresceu na última década. Com o licenciamento e aprovação do Restylane pela Food and Drug Administration (Medicis, Scottsdale, AZ) no ano de 2003, ocorrendo grande demanda de números de pessoas que procuraram o melhoramento estético utilizando o ácido Hialurônico. Com a grande quantidade de pessoas que aderiram a esse meio de rejuvenescimento, consequentemente ocorreu o aumento de forma proporcional ao número de complicações relacionadas aos comprometimentos vasculares relacionados a essas injeções (NERI SRNG, et al., 2013). 
Tabela 1 - Delineamento, métodos e principais desfechos dos estudos selecionados.

\begin{tabular}{|c|c|c|c|c|}
\hline Autor & Ano & Idioma & Objetivo & Resultados \\
\hline RIOS M & 2017 & Brasil & $\begin{array}{l}\text { A odontologia moderna, em sua atuação } \\
\text { no meio estético, colabora também para } \\
\text { o melhoramento dos fatores psicológicos } \\
\text { e na qualidade de vida do paciente. }\end{array}$ & $\begin{array}{l}\text { Dentre os materiais utilizados para preenchimento facial } \\
\text { estão a toxina botulínica, os fios de sustentação, a } \\
\text { bichectomia, o ácido hialurônico e o PMMA } \\
\text { (Polimetilmetacrilato). }\end{array}$ \\
\hline DELORENZI C & 2017 & Canadá & $\begin{array}{l}\text { O objetivo deste artigo é atualizar as } \\
\text { alterações nos protocolos do autor } \\
\text { usados para gerenciar eventos } \\
\text { vasculares } \text { relacionados ao } \\
\text { preenchimento agudo daqueles } \\
\text { publicados anteriormenter nesta } \\
\text { revista. Por falta de um termo melhor, } \\
\text { esse novo protocolo foi denominado } \\
\text { protocolo de hialuronidase pulsada em } \\
\text { alta dose (HDPH) para eventos } \\
\text { embólicos vasculares com cargas de } \\
\text { ácido hialurônico (HA). }\end{array}$ & $\begin{array}{l}\text { A dosagem do HYAL varia conforme a quantidade de tecido } \\
\text { isquêmico, consistente com a nova hipótese subjacente de } \\
\text { que devemos inundar os vasos ocluídos com uma } \\
\text { concentração suficiente de HYAL por um período de tempo } \\
\text { suficiente, a fim de dissolver a obstrução do AH até o ponto } \\
\text { em que os produtos hidrólise pode passar através dos leitos } \\
\text { capilares. Embora os eventos embólicos vasculares sejam } \\
\text { raros, é importante observar que a face possui áreas de } \\
\text { maior risco e menor risco para o tratamento de de } \\
\text { preenchimento, mas não há áreas de "risco zero" com } \\
\text { relação aos tratamentos de preenchimento. Mesmo com } \\
\text { bom conhecimento anatômico e técnica correta, ainda existe } \\
\text { um risco diferente de zero de eventos embólicos vasculares } \\
\text { (incluindo injetores experientes e altamente qualificados). }\end{array}$ \\
\hline CROCCO EI & 2012 & Brasil & $\begin{array}{l}\text { O objetivo do trabalho é auxiliar o } \\
\text { reconhecimento dos efeitos colaterais } \\
\text { com uso de preenchedor à base de ácido } \\
\text { hialurônico. Isso permite diagnóstico e } \\
\text { tratamento precoces, diminuindo a } \\
\text { morbidade e sequelas dos pacientes. }\end{array}$ & $\begin{array}{l}\text { Nos últimos anos, o uso de preenchedores para tratamento } \\
\text { de rítides e aumento do volume facial cresceu } \\
\text { consideravelmente. Há atualmente diferentes tipos de } \\
\text { preenchedores, divididos em temporários, semipermanentes } \\
\text { (permanência de no mínimo } 18 \text { meses no tecido) e } \\
\text { permanentes, também classificados conforme a composição } \\
\text { do material (colágeno, ácido hialurônico, ácido polilático, } \\
\text { polimetilmetacrilato, hidroxiapatita); o ácido hialurônico pode } \\
\text { ser sintético ou de origem animal. Dos diversos produtos, o } \\
\text { ácido hialurônico (preenchedor reabsorvível, temporário) tem } \\
\text { sido um dos mais utilizados. Ainda não há disponível no } \\
\text { mercado substância ideal, pura e livre de efeitos colaterais. }\end{array}$ \\
\hline
\end{tabular}

\footnotetext{
REAS/EJCH | Vol.Sup.n.39 | e2296 | DOI: https://doi.org/10.25248/reas.e2296.2020 Página 5 de 9
} 


\begin{tabular}{|c|c|c|c|c|}
\hline NAST A, et al. & 2011 & Alemanha & $\begin{array}{l}\text { Avaliação da eficácia e segurança de } \\
\text { ambos os produtos utilizando } \\
\text { hialuronidase. }\end{array}$ & $\begin{array}{l}\text { Ambos os produtos mostraram bons resultados imediatos } \\
\text { após a injeção e o retoque e demonstraram boa durabilidade } \\
\text { ao longo do tempo. A preferência dos participantes pelo } \\
\text { tratamento opcional no final do estudo favoreceu o mono- } \\
\text { HA. Ambos os produtos foram bem tolerados, sem eventos } \\
\text { adversos graves. }\end{array}$ \\
\hline NERI SRNG, et al. & 2013 & Brasil & $\begin{array}{l}\text { O uso do ácido hialurônico }(\mathrm{AH}) \text { injetável } \\
\text { no preenchimento de rugas e } \\
\text { volumização facial está consagrado na } \\
\text { prática dermatológica. O manejo de suas } \\
\text { complicações, embora raras, deve ser do } \\
\text { conhecimento do dermatologista. }\end{array}$ & $\begin{array}{l}\text { No uso dos preenchedores de aplicação mais profunda, a } \\
\text { formação de nódulos pode ocorrer, e a conduta é similar à } \\
\text { utilizada para preenchedores mais superficiais e menos } \\
\text { viscosos. O uso da cânula mais fina possivelmente reduz } \\
\text { esse risco, sobretudo em áreas de derme mais fina. }\end{array}$ \\
\hline $\begin{array}{l}\text { SANTONI MTS, } \\
\text { COLET CF }\end{array}$ & 2018 & Brasil & $\begin{array}{l}\text { destacar as várias características e } \\
\text { apresentações desse polissacarídeo. } \\
\text { Como resultado, o AH apresentou-se } \\
\text { como um bom preenchedor facial, tendo } \\
\text { um tempo de duração esperado, havendo } \\
\text { poucos efeitos colaterais e se adaptando } \\
\text { aos contornos faciais. }\end{array}$ & $\begin{array}{l}\text { Trata-se de um polissacarídeo da família dos } \\
\text { glicosaminoglicanos (GAG), presente no tecido conjuntivo } \\
\text { dos humanos, que diminui com o passar da idade, } \\
\text { contribuindo para a formação de rugas e a diminuição da } \\
\text { elasticidade da pele. Para minimizar tais danos pode-se } \\
\text { utilizar o AH com fins estéticos, pois esse ácido tem uma } \\
\text { grande atividade higroscópica, o qual confere volume, } \\
\text { sustentação, hidratação e elasticidade a pele, retardando, } \\
\text { assim os sinais de envelhecimento }\end{array}$ \\
\hline BRODY HJ & 2011 & EUA & $\begin{array}{l}\text { Avaliar o uso de hialuronidase no } \\
\text { tratamento de reações alérgicas e o } \\
\text { extravio incorreto de ácido hialurônico na } \\
\text { pele. }\end{array}$ & $\begin{array}{l}\text { O uso de hialuronidase reduziu o desconforto do paciente em } \\
24 \text { a } 48 \text { horas, impedindo qualquer ansiedade ou insatisfação } \\
\text { do paciente. }\end{array}$ \\
\hline
\end{tabular}

Fonte: Neto JMAS, et al., 2019. 
O desenvolvimento de nódulos ou leves inchaços logo depois da injeção do ácido hialurônico, devido à falta e manuseio ou por causa do excesso no local aplicado, é caracterizado como adversidades de complicações em pequeno espaço de tempo e são um pouco raras de acontecerem, entre outras causas adversas observadas, visto que a quantidade de intercorrências ocasionadas por preenchedores, especificamente o AH já é extremamente baixo, inferior a 1\% (CROCCO El, 2012).

O processo relacionado a isquemia cutânea caracteriza-se como sendo uma das intercorrências de maior agravo e importuno ocasionado logo após as aplicações injetáveis de $\mathrm{AH}$ em processos de realização estética que buscam o rejuvenescimento e volumização orofacial. Tais incidentes são ocasionados pela embolia arterial de ácido hialurônico ou até mesmo devido a oclusão por constrição, geralmente os resultados são manifestados assim que o AH é aplicado possuindo por sua vez efeitos imediatos, isso faz com quer o profissional obtenha um diagnóstico clínico na mesma sessão (SANTONI MTS e COLET CF, 2018). As variações dessas intercorrências são bastante diversificadas, desde um possível eritema e até mesmo uma necrose tecidual, sendo esse segundo mais raro de acontecer. A utilização da enzima hialuronidase em proporções e concentrações corretas fazem com quer o processo de degradações teciduais e a recuperação do fluxo sanguíneo local seja retomado (DELORENZI C, 2017).

Os efeitos adversos ocasionados pelo AH pode ocasionar além de desconfortos o grande risco de danos irreparáveis para os pacientes que não busquem soluções reparatórias imediatas. Estudos comprovam que a utilização da enzima hialuronidase em tempos diferentes ocasionam resultados dessemelhantes para a correção e reversão do quadro clínico do paciente, concluindo que a degradação o quanto mais precoce for, a obtenção do resultado é mais acelerada e satisfatória (DELORENZI C, 2017), (CROCCO EI, 2012).

Segundo Santoni MTS e Colet CF (2018), a utilização do ácido hialurônico injetáveis em procedimentos realizados na derme não está livre de intercorrências relacionadas a reações adversas que possam a vim acontecer. Em estudos analisados constatou-se relatos de casos que ocasionou pequenas reações inflamatórias no tecido aplicado, deixando pequenos hematomas, vermelhidão da pele que são comuns, abscessos nos locais de aplicação podendo ocasionar nódulos, necrose tecidual e por consequência algumas cicatrizes teciduais (NAST A, et al., 2011), (NERI SRNG, et al., 2013). A hialuronidase atua no processo de despolimerização fazendo com quer a aplicação do $\mathrm{AH}$ seja reversível, esse processo químico ocorre devido a seus componentes ficarem alojados em torno das células do tecido conjuntivo, consequentemente acarretando temporariamente a viscosidade do tecido e deixando-o mais propício à sua disseminação de líquidos. De acordo com esses fundamentos existem os processos de ações da enzima (NERI SRNG, et al., 2013).

O maior risco na aplicação do $\mathrm{AH}$ é referente a região da glabela como mostra o estudo feito por Nast $A$, et al. (2011), sendo concordado por Almeida ART e Sampaio GAA, (2016), onde eles afirmam que devido a glabela possuir a maior predisposição de comprometimento maior de vasos importante, pode-se ocasionar no respectivo local uma maior possibilidade de necrose tecidual e se por algum motivo o aplicador pegar um vaso profundo pode comprometer até mesmo a visão do paciente, outro aspecto importante a ser levado em consideração é que os feixes vasculares das veias supratroclear e supraorbitárias inervam diretamente a glabela, ocasionando no ato da aplicação uma diminuição no fornecimento do sangue no local, o profissional tem que ficar bastante, se preciso for aplicar a hialuronidase.

Para evitar os efeitos colaterais precoces e tardios inúmeros aspectos tem que serem levados em consideração antes da aplicação do AH como: uma anamnese bastante detalhada, sendo levado em consideração todas as respostas do paciente, sem deixar passar despercebidos fatores que sejam limitantes para o processo de aplicação, o exame de compatibilidade biológica, as margens de seguranças que irão ser efetuadas no paciente, sabendo-se que ela varia de paciente para paciente, o equilíbrio do Cirurgião Dentista no ato da aplicação, buscando dessa forma diminuir riscos de alergias, reações inflamatórias (SILVA RM e ANDREATA MFG, 2017).

Destaca-se que em muitos dos casos onde são observados efeitos adversos, o paciente apresenta em testes alergológicos com resultados positivos possuindo sensibilidade as picaduras de abelhas e vespas sendo contraindico o uso da hialuronidase, já que a enzima é uma substância ativa. Além do mais, não se 
pode utilizar essas enzimas que foram produzidas de fonte animal, se o paciente possuir relato histórico dessas respectivas alergias. (BORCHARD K, et al., 2010).

Em termos científicos observa-se que a proporção utilizada ácido hialurônico na efetivação da aplicação gera em torno de $1 \mathrm{ml}$, para o profissional obter uma margem de boa segurança o máximo prescrito nas bulas e literaturas é de $2 \mathrm{ml}$. Na grande maioria dos casos $1 \mathrm{ml}$ do produto já é o bastante para um resultado satisfatório. Se o profissional ou o paciente não ficar satisfeitos com o resultado esperado é indicado fazer nova aplicação em sessões subsequentes e não no mesmo dia, dessa forma obtêm-se uma margem de segurança adequada, se o profissional aplicar a mais do que o esperado pelo paciente é importante utilizar a hialuronidase o mais rápido possível (GOMES RK e GABRIEL M, 2006).

O desenvolvimento de possíveis nódulos ocasionados devido a decorrência de alguma falha no processo de preenchimento de $\mathrm{AH}$, como por exemplo devido seu acúmulo no respectivo local de aplicação, é ressaltada na literatura como sendo uma falha precoce e bastante rara, já que acomete menos de $1 \%$ dos pacientes que passam por esses procedimentos, apesar de que o nódulo em si, devido a grande concentração do produto, não represente impreterivelmente uma complicação grave, sendo indesejável esteticamente, tendo essa ótica a respeito da problematização é necessário que o CD procure um tratamento de imediato, sendo ágil e cuidadoso na técnica que irá utilizar, buscando preservar o resultado obtido durante o tratamento estético, principalmente quando demonstra um efeito Tyndall (CARRUTHERS J e CARRUTHERS A, 2003).

Para uma boa correção de possíveis nódulos ou granulomas é adequado a aplicação de hialuronidase sendo esse o tratamento de primeira escolha, isso ocorre porque seus princípios ativos agem com bastante intensidade no local desejado e seus resultados são superiores quando se compara com corticoides (SANTONI MTS e COLET CF, 2018). A hialuronidase atua no processo de despolimerização revertendo o $\mathrm{AH}$ acumulado em torno das células do tecido conjuntivo, minimizando a viscosidade temporária desse tecido, deixando-o com uma forma mais permeável na disseminação dos líquidos. Com base nesse fator ela é utilizada para estabelecer a diminuição do AH injetado. No Brasil, a mais utilizada é a Hyalozima 20.000UTR (Apsen) que, depois ser submetida a diluição em solvente que vem junto com ela, apresenta-se 4.000UTR por $1 \mathrm{ml}$ (SCLAFANI AP e FAGIEN S, 2009).

A utilização, no entanto, precisa de muita cautela, para precaver a hidrólise do AH, o que decorreria clinicamente em aparência atrófica e depressiva, por isso, todo Cirurgião Dentista que possui capacitação de executar o procedimento de harmonização facial precisa dominar a técnica de aplicação como pode ser analisado no Fluxograma 1 (HIRSCH RJ, et al, 2007).

Fluxograma 1 - Técnica de aplicação da enzima Hialuronidase.

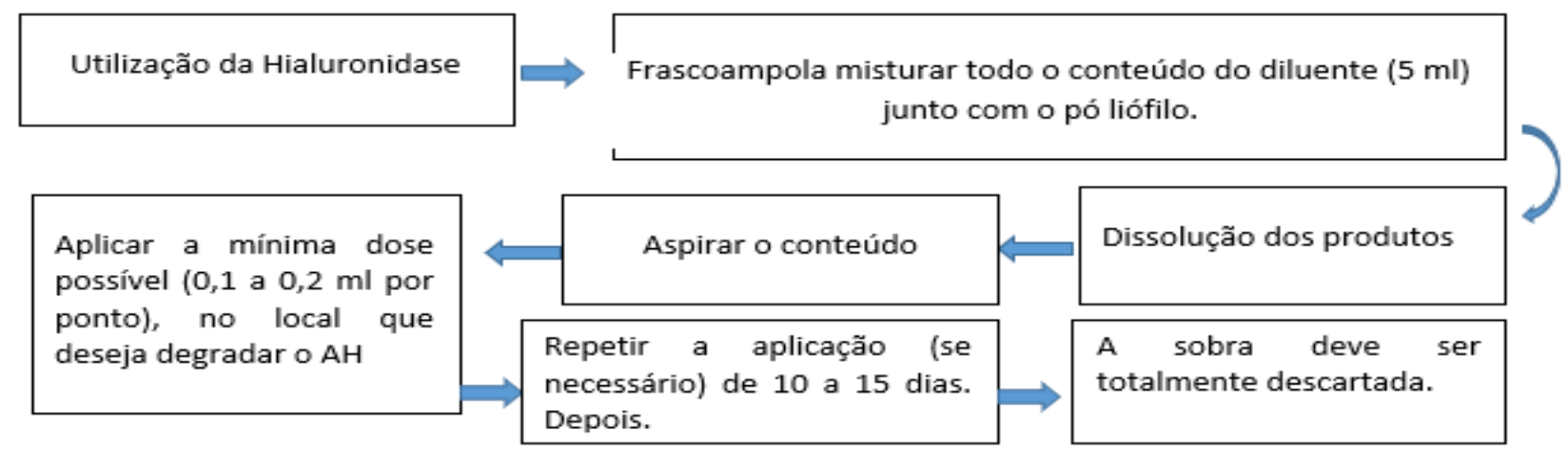

Fonte: Hirsch RJ, et al., (2007) modificada por Neto JMAS, et al., (2019).

Harold J, (2011), ressalta que essa técnica é semelhante com a técnica de Brody, a diferença entre as duas ocorre no intervalo de tempo, onde tem que haver uma aplicação de 5 em 5 minutos e analisar se nesse espaço de tempo ocorreu algum edema, devido a hipersensibilidade a essa substância, a literatura ressalta que é rara, porém pode acontecer, por isso é bom fazer uma anamnese aprofundada. 


\section{CONSIDERAÇÕES FINAIS}

A hialuronidase é uma enzima bastante importante nos recursos terapêuticos quando é decorrido eventuais complicações na aplicação do ácido hialurônico aplicados pelo Cirurgião Dentista, desde que seja empregada meticulosamente. Para sua aplicação é necessário que o CD faça uma aprofundada anamnese no paciente, buscando saber históricos de alergias desse derivado, possua boa habilidade de manuseamento além de conhecer todos os princípios ativos que constituem essa enzima, visto que ela degrada o ácido hialurônico, estando como fundamental foco nessa revisão integrativa demostrar os benefícios e a técnica de sua aplicação, porém é necessário mais pesquisas cientificas para poder estabelecer os parâmetros corretos para várias concentrações de hialuronidase, tendo como proposito contribuir cientificamente a respeito dessa temática.

\section{REFERÊNCIAS}

1. ALMEIDA ART, SAMPAIO GAA. Ácido hialurônico no rejuvenescimento do terço superior da face: revisão e atualização - Parte 1. Surgical \& Cosmetic Dermatology, São Paulo, 2016; v.8, n.2, p.148-153.

2. BALASSIANO LKA, BRAVO BSF. Hialuronidase: uma necessidade de todo dermatologista que aplica ácido hialurônico injetável. SurgCosmetDermatol. 2014; 6(4):338-43.

3. BORCHARD K, et al. Hyaluronidase allergy: a rare cause of periorbital inflammation. Australas J Dermatol. 2010; 51(1):49-51.

4. BRODY HJ. Use of Hyaluronidase in the Treatment of Granulomatous Hyaluronic Acid Reactions or Unwanted Hyaluronic Acid Misplacement. Dermatol Surg. 2011; 31(8): 893-7.

5. CARRUTHERS J, CARRUTHERS A. A prospective, randomized, parallel group study analyzing the effect of BTX-A and nonanimal sourced hyaluronic acid in combination compared with NASHA alone in severe glabellar rhytides in adult female subjects. Dermatol Surg.2003; 29(8):802-9

6. CROCCO El, et al. Eventos adversos do ácido hialurônico injetável. Surgical \& Cosmetic Dermatology, São Paulo, 2012; v.4, n.3, p.259-263.

7. DELORENZI C. New High Dose Pulsed Hyaluronidase Protocol for Hyaluronic Acid Filler Vascular Adverse Events. Aesthet Surg J.2017; 37(7):814-25.

8. FERREIRA NR, CAPOBIANCO MP. Uso do ácido hialurônico na prevenção do envelhecimento facial. 2016.

9. GOMES RK, GABRIEL M. Cosmetologia: Descomplicando os Princípios Ativos. 1ª ed. São Paulo. Livraria Médica Paulista Editora, 2006.

10. GOODMAN GJ, et al. Current Concepts in the Use of Voluma, Volift, and Volbella.Plast Reconstr Surg. $2015 ; 136$ (5):139S-148S.

11. HIRSCH RJ, et al. Hyaluronidase in the office: a necessity for every dermasurgeon that injects hyaluronic acid. J Cosmet Laser Ther. 2007; 9(3):182-5.

12. MONTEIRO EO. Tratamento de rejuvenescimento facial com ácido hialurônico não estabilizado de origem não animal aplicado na derme. Moreira Jr. Editora; 198 a 200. Revista Brasileira de Medicina, 2011; v. 68, n 6.

13. NAST A, et al. Efficacy and durability of two hyaluronic acid-based fillers in the correction of nasolabial folds: results of a prospective, randomized, double-blind, actively controlled clinical pilot study. Dermatol Surg. 2011; 37(6):768-75.

14. NERI SRNG, et al. Uso de hialuronidase em complicações causadas por ácido hialurônico para volumização da face: relato de caso. Surg Cosmet Dermatol 2013; 5(4):364-6.

15. PARK TH, et al. Clinical experience with hyaluronic acid-filler complications. J Plast Reconstr Aesthet Surg. 2011; 64(7):892-96.

16. RIOS M. Harmonização orofacial: um novo conceito na odontologia. São Paulo: Artes Médicas, 2017

17. SANTONI MTS, COLET CF. Uso de ácido hialurônico injetável na estética facial: uma revisão da literatura. UNIJUÍ Universidade Regional do Noroeste do Estado Do Rio Grande Do Sul. ljuí - RS. 2018.

18. SCHNEIDER LV. Estrutura da Pele e seus Anexos. Curso Extensivo de Cosmetologia, Porto Alegre: 2000; v.1, n. 5, p.2-13.

19. SCLAFANI AP, FAGIEN S. Treatment of injectable soft tissue filler complications. Dermatol Surg. 2009 ; 35 (Suppl 2):1672-80.

20. SILVA RM, ANDREATA MFG. Rejuvenescimento facial: a eficácia da radiofrequência associada à vitamina $C$. Revista Maiêutica, Santa Catarina, 2017; v.1, n.1, p. 55-73. 